\title{
Comparação entre método bioquímico e reação em cadeia de polimerase para identificação de Lactobacillus spp., isolados de aves
}

\author{
[Comparison between biochemical and polymerase chain reaction methods for the identification \\ of Lactobacillus spp. isolated from chickens] \\ M.R. Barros ${ }^{1}$, R.L. Andreatti Filho ${ }^{1}$, D.E. Oliveira ${ }^{2}$, E.T. Lima ${ }^{1}$, A.J. Crocci ${ }^{3}$ \\ ${ }^{1}$ Faculdade de Medicina Veterinária e Zootecnia - UNESP \\ Distrito de Rubião Júnior \\ 18618-000 - Botucatu, SP \\ ${ }^{2}$ Faculdade de Medicina - UNESP - Botucatu, SP \\ ${ }^{3}$ Instituto de Biociências - UNESP - Botucatu, SP
}

\begin{abstract}
RESUMO
Lactobacilos foram isolados do inglúvio e cecos de reprodutoras pesadas e caracterizados como Grampositivo, catalase negativo, produtores de gás em glicose e não produtores de $\mathrm{H}_{2} \mathrm{~S}$ em triple sugar iron e pela fermentação de carboidratos. Utilizaram-se os iniciadores: Lac 1/23-10C para detecção de Lactobacillus acidophilus, L. crispatus, L. amylovorus, L. gasseri, L. helveticus e L. jensenii; Lac 2/LU-1' para L. acidophilus; Fer 3/Fer 4 para L. fermentum; Reu 1/Reu 2 para $L$. reuteri e Sal 1 e Sal 2 para $L$. salivarius. L. reuteri e L. salivarius foram identificados pela reação em cadeia de polimerase (PCR) e pelo teste bioquímico, enquanto $L$. acidophilus, $L$. fermentum e Lactobacillus sp. somente pelo teste bioquímico. Os resultados obtidos na PCR foram mais precisos quando comparados aos obtidos com o método bioquímico, que demonstrou ser subjetivo devido às variações na fermentação de carboidratos, principalmente na diferenciação entre L. fermentum e L. reuteri.
\end{abstract}

Palavras-chave: galinha, reprodutora de frango de corte, identificação bioquímica, Lactobacillus, PCR

\begin{abstract}
Lactobacilli were isolated from crops and ceca of broiler breeders and characterized by positive Gram staining, negative catalase test, production of gas from glucose, and negative for $\mathrm{H}_{2} \mathrm{~S}$ production from triple sugar iron, and carbohydrates fermentation. Primers: Lac1/23-10C for detecting Lactobacillus acidophilus, L. crispatus, L. amylovorus, L. gasseri, L. helveticus, and L. jensenii; Lac2/LU-1' for L. acidophilus; Fer3/Fer4 for L. fermentum; Reu1/Reu2 for L. reuteri, and Sal1/Sal2 for L. salivarius were used. L. reuteri and L. salivarius were identified by both polymerase chain reaction (PCR) and biochemical tests. However, L. acidophilus, L. fermentum, and Lactobacillus $s p$. were only identified by biochemical tests. PCR results were more precise, considering the variability of carbohydrate fermentation among the strains, especially for identifying $\mathrm{L}$. fermentum and $\mathrm{L}$. reuteri.
\end{abstract}

Keywords: chicken, broiler breeders, biochemical identification, Lactobacillus, PCR

\section{INTRODUÇ̃̃̃O}

A colonização da mucosa intestinal é composta por grande e diversificado número de bactérias, sendo considerada normal no homem e nos animais, incluindo as aves (Miles, 1993). Dentre os principais gêneros bacterianos identificados nesta microbiota, invariavelmente é observada a presença de Lactobacillus spp. (Salanitro et al., 1978; Oyarzabal e Conner, 1995).

Os Lactobacillus são componentes importantes da microbiota do trato respiratório (Kawaguchi et al., 1991), inglúvio (Sarra et al., 1992) e intestinos de aves. Dentre os Lactobacillus heterofermentativos intestinais, o L. fermentum

Recebido em 21 de setembro de 2007

Aceito em 16 de março de 2009

E-mail: merciarbpe@yahoo.com.br 
foi considerado por Lerche e Reuter (1962) como espécie dominante nos intestinos. Kandler et al. (1980) descreveram este biótipo, segundo dados de homologia genômica, como uma nova espécie heterofermentativa denominada $L$. reuteri. As espécies de $L$. fermentum e L. reuteri são fenotipicamente relacionadas, e sua diferenciação baseada em métodos bioquímicos é duvidosa (Reuter, 1997).

O gênero Lactobacillus é composto por mais de 60 espécies, cuja identificação de acordo com critérios fisiológicos e bioquímicos, é trabalhosa e ambígua (Kandler e Weiss, 1986; Nour, 1998).

Métodos moleculares de análise do genoma bacteriano são úteis para se diferenciar essas duas espécies, sendo importantes para a classificação taxonômica (Klein et al., 1998). O desenvolvimento de protocolos de identificação baseados na reação em cadeia de polimerase (PCR) tem gerado novas possibilidades para identificação precisa e rápida das bactérias acidoláticas (Torriane et al., 1999).

A importância das espécies de Lactobacillus nos processos industriais ou na saúde humana e animal tem estimulado o desenvolvimento de métodos de genética molecular para identificação de espécies desse gênero (Chagnaud et al., 2001).

O objetivo do presente trabalho foi isolar e identificar Lactobacillus spp. de aves por meio do teste bioquímico e PCR.

\section{MATERIAL E MÉTODOS}

Foram utilizadas 12 aves reprodutoras comerciais da linhagem Ross, com 52 e 65 semanas de idade, como doadoras de inglúvio e cecos. Imediatamente após o sacrifício por deslocamento cervical das aves, foram coletados assepticamente o inglúvio e cecos, que foram colocados individualmente em tubos contendo $10 \mathrm{~mL}$ de caldo MRS $\mathrm{pH}$ 6,5. Os tubos foram incubados a $37^{\circ} \mathrm{C}$ por 48 horas e a $37^{\circ} \mathrm{C}$ e $45^{\circ} \mathrm{C}$ por 12 e 18 horas em condições de anaerobiose (Anaerobac). Após esse período, os caldos foram semeados em placas de Petri contendo ágar MRS e incubados a $37^{\circ} \mathrm{C}$ por 24 e 48 horas.

Para verificação da pureza das estirpes, realizouse o plaqueamento bacteriano em ágar DeMan,
Rugosa-Sharpe (MRS) ${ }^{1}$, cultivados em jarra de anaerobiose contendo o sistema Anaerobac ${ }^{2}$, com incubação a $37^{\circ} \mathrm{C}$ por 48 horas. Posteriormente, as colônias de cada estirpe foram submetidas às provas de coloração de Gram (Pelczar et al., 1981), teste de catalase (Sharpe, 1981), produção de gás em glicose (Collins e Hartlein, 1982) e produção de sulfeto de hidrogênio $\left(\mathrm{H}_{2} \mathrm{~S}\right)$ em açúcar triple sugar iron (TSI), conforme Sneath et al. (1986).

Para a realização do teste bioquímico, as estirpes isoladas de aves (EIAs) foram semeadas em caldo MRS modificado (sem extrato de carne e glicose, adicionando-se $0,002 \%$ de púrpura de bromocresol como indicador) e acréscimo individual de $1 \%$ de um dos seguintes carboidratos: arabinose, celobiose, esculina, frutose, galactose, glicose, lactose, manitol, maltose, manose, rafinose, sacarose, salicina, sorbitol, trealose e xilose, incubadas a $37^{\circ} \mathrm{C}$ por 48 horas (Kandler e Weiss, 1986).

Foram utilizadas como controle estirpes de referência de Lactobacillus acidophilus da Korean Collection for Type Cultures, \#KCTC3111, obtidas do Instituto de Tecnologia de Alimentos, e de L. fermentum (CCT 2571), $L$. reuteri (CCT 3433) e L. salivarius (CCT 3752) da Coleção de Cultura Tropical, obtidas da Fundação Tropical de Pesquisas e Tecnologia "André Tosello".

Todas as estirpes de referência e $10 \%$ das EIAS foram semeadas no API $50 \mathrm{CHL}^{\circledR}$, incubadas aerobicamente a $37^{\circ} \mathrm{C}$ por 48 horas.

A extração do DNA das amostras foi realizada segundo a metodologia descrita por Oliveira et al. (2006). Em síntese, $250 \mu \mathrm{L}$ da suspensão bacteriana proveniente do caldo MRS acondicionados em tubo de microcentrífuga $1,5 \mathrm{~mL}$ foram acrescidos de $100 \mu \mathrm{L}$ de cloreto de sódio $5 \mathrm{M}$ e $100 \mu \mathrm{L}$ de solução $\mathrm{CTAB} / \mathrm{NaCl}$ préaquecida a $65^{\circ} \mathrm{C}$. Após agitação e incubação das amostras por $10 \mathrm{~min}$ a $65^{\circ} \mathrm{C}$, realizou-se purificação do DNA extraído com solução clorofórmio/álcool-isoamílico 24:1. As amostras foram homogeneizadas e, em seguida,

${ }^{1}$ Difco - Kansas, EUA.

${ }^{2}$ Probac do Brasil - São Paulo, Brasil. 
centrifugadas por $5 \mathrm{~min}$ a $20.800 \mathrm{x}$ g temperatura ambiente. $\mathrm{O}$ sobrenadante obtido foi transferido para um novo tubo, ao qual foi adicionado etanol absoluto gelado $\left(-20^{\circ} \mathrm{C}\right)$. Depois de incubadas por $10 \mathrm{~min}$ a $-20^{\circ} \mathrm{C}$, as amostras foram centrifugadas a $4^{\circ} \mathrm{C}$ por $20 \mathrm{~min}$ a $20.800 \mathrm{x}$ g para precipitação do DNA. Após remoção do etanol absoluto, o DNA precipitado foi lavado com etanol $70 \%$ (temperatura ambiente) e centrifugado a $20.800 \mathrm{x}$ g por $10 \mathrm{~min}$, repetindose esse procedimento por duas vezes. Após secagem a $56^{\circ} \mathrm{C}$ por $15 \mathrm{~min}$ em banho-seco, o pélete de DNA foi ressuspendido em $50 \mu \mathrm{L}$ de solução TE (Tris-HCL $10 \mathrm{mM} /$ EDTA $1 \mathrm{mM}$ ) pH 8,0. As amostras de DNA foram quantificadas por espectrofotometria, normalizadas a $0,1 \mu \mathrm{g} / \mu \mathrm{L}$ e estocadas a $-20^{\circ} \mathrm{C}$ até a sua utilização na PCR.

Os iniciadores utilizados são apresentados na Tab. 1. Inicialmente, as amostras foram submetidas à PCR multiplex (reação A) para triagem das estirpes $L$. fermentum, L. reuteri e $L$. salivarius. Amostras negativas nessa triagem foram avaliadas em PCR com os iniciadores Lac1 e 23-10C, que amplificam segmento do genoma de L. acidophilus, e os iniciadores grupo-específicos Lac2 e LU-1', que amplificam região conservada do genoma das estirpes $L$. acidophilus, L. amylovorus, L. crispatus, $L$. gasseri, L. helveticus e L. jensenii (reação B). Os componentes das PCRs e o perfil de ciclagem estão indicados na Tab. 2. Em todos os experimentos, foram utilizados controles positivos (DNA extraído das estirpes-referência) e negativos (reação contendo todos os componentes da PCR, exceto DNA bacteriano). $\mathrm{O}$ produto da PCR foi avaliado por meio de eletroforese em gel de agarose contendo $2 \%$ de brometo de etídio e marcadores de peso molecular, com intervalos de tamanhos moleculares de $50 \mathrm{pb}$ ou $100 \mathrm{pb}$.

Tabela 1. Iniciadores para identificação das estirpes estudadas de Lactobacillus

\begin{tabular}{llc}
\hline \multicolumn{1}{c}{ Microrganismo } & \multicolumn{1}{c}{ Iniciadores $\left(5^{\prime}-3^{\prime}\right)$} & Amplicon \\
\hline $\begin{array}{l}\text { L. acidophilus, L. amylovorus, } \\
\text { L. crispatus, L. gasseri, L. } 1 \text { CCTCTTCGCTCGCCGCTACT } \\
\text { helveticus e L. jensenii }\end{array}$ & 23-10C: ATTGTAGAGCGACCGAGAAG & $300 \mathrm{pb}$ \\
& & \\
L. acidophilus & Lac 2: TGCAAAGTGGTAGCGTAAGC & \\
& LU-1': CCTTTCCCTCACGGTACTG & $210 \mathrm{pb}$ \\
L. fermentum & Fer 3:ACTAACTTGACTGATCTACGA & $192 \mathrm{pb}$ \\
& Fer 4: TTCACTGCTCAAGTAATCATC \\
L. reuteri & Reul: CAGACAATCTTTGATTGTTTAG & $303 \mathrm{pb}$ \\
L. salivarius & Reu4: GCTTGTTGGTTTGGGCTCTTC & \\
& Sall: AATCGCTAAACTCATAACCT & $411 \mathrm{pb}$ \\
\hline
\end{tabular}

(Song et al., 2000)

Tabela 2. Composição das reações e perfil de termociclagem para identificação de estirpes de Lactobacillus

\begin{tabular}{|c|c|c|}
\hline PCR/Iniciador & Composição & Perfil de termociclagem \\
\hline Reação A & Tampão para PCR 1x, 2,50mM de & $94^{\circ} \mathrm{C}-5 \min (1 \mathrm{x}) ; 94^{\circ} \mathrm{C}-1 \mathrm{~min}, 57^{\circ} \mathrm{C}-$ \\
\hline Fer3, Fer4, Reu1, & cloreto de magnésio, $0,20 \mathrm{mM}$ de & $30 \mathrm{~s}, 72^{\circ} \mathrm{C}-1 \mathrm{~min}(40 \mathrm{x}) ; 72^{\circ} \mathrm{C}-$ \\
\hline Reu4, Sal1 e Sal2 & $\begin{array}{l}\text { dNTPs, } 0,4 \mu \mathrm{M} \text { de cada iniciador, } 1,25 \mathrm{U} \\
\text { de Taq DNA polimerase e } 2 \mu \mathrm{L} \text { de DNA } \\
\text { a } 0,1 \mu \mathrm{g} / \mu \mathrm{L} \text { em } 25 \mu \mathrm{L} \text { de reação. }\end{array}$ & $7 \min (1 x)$ \\
\hline $\begin{array}{l}\text { Reação B } \\
L a c 1,23-10 C \\
L a c 2 \text { e } L U-1\end{array}$ & Idem acima & Idem acima \\
\hline
\end{tabular}


Para comparação do método bioquímico e PCR na identificação dos isolados provenientes do inglúvio e cecos, usaram-se os testes de McNemar e qui-quadrado (Zar, 1996).

\section{RESULTADOS E DISCUSSÃO}

Todas as 366 estirpes que se revelaram positivas no teste de coloração de Gram, negativas no teste de catalase, positivas na produção de gás em glicose e negativas na produção de $\mathrm{H}_{2} \mathrm{~S}$ em TSI foram consideradas compatíveis com o gênero Lactobacillus.

A leitura da fermentação dos carboidratos referente ao teste bioquímico foi realizada por meio da tabela do manual Bergey's para identificação de espécies. Os isolados, obtidos do inglúvio e cecos das aves, foram identificados no teste bioquímico como L. acidophilus, $L$. fermentum, $L$. reuteri, $L$. salivarius ou Lactobacillus sp., e na PCR foram detectados $L$. reuteri e L. salivarius. (Tab. 3).

Tabela 3. Identificação das espécies de Lactobacillus isoladas do inglúvio e cecos de aves, por meio do método bioquímico e pela reação em cadeia da polimerase (PCR)

\begin{tabular}{ccccccc}
\hline Órgão & L. acidophilus & L. fermentum & L. reuteri & L. salivarius & Lactobacillus sp. & Método \\
\hline Inglúvio & $24 \mathrm{a}$ & $59 \mathrm{a}$ & $22 \mathrm{a}$ & $21 \mathrm{a}$ & $54 \mathrm{a}$ & Bioquímico \\
& $0 \mathrm{~b}$ & $0 \mathrm{~b}$ & $104 \mathrm{~b}$ & $35 \mathrm{~b}$ & $0 \mathrm{~b}$ & PCR \\
Ceco & $18 \mathrm{a}$ & $66 \mathrm{a}$ & $26 \mathrm{a}$ & $27 \mathrm{a}$ & $49 \mathrm{a}$ & Bioquímico \\
& $0 \mathrm{~b}$ & $0 \mathrm{~b}$ & $133 \mathrm{~b}$ & $17 \mathrm{a}$ & $0 \mathrm{~b}$ & PCR \\
\hline
\end{tabular}

Para cada órgão e cada espécie: valores seguidos de letras distintas na coluna diferem entre si $(\mathrm{P}<0,05)$ pelos testes McNemar e qui-quadrado (Zar, 1996).

Lerche e Reuter (1962) isolaram L. fermentum e consideraram ser espécie dominante no intestino, sendo a mesma considerada como referência. Contudo, Kandler e Weiss (1986), por meio da homologia DNA-DNA, descreveram esse biótipo como uma nova espécie de Lactobacillus heterofermentativo, identificada como L. reuteri.

Dentre as estirpes de referência identificadas pelo kit bioquímico API $50 \mathrm{CHL}$, L. reuteri (CCT 3433) apresentou como resultado $L$. fermentum com $92,8 \%$ de confiabilidade, concordando com Chagnaud et al. (2001) que obtiveram resultado semelhante com a utilização do API 50 CHL para identificação de L. reuteri, sendo considerada como $L$. fermentum com (96,9\%) de confiabilidade. Na PCR, entretanto, (Fig. 1) houve uma simples identificação dessa estirpe como L. reuteri, mostrando que essas duas espécies não podem ser diferenciadas apenas pela fermentação de carboidratos. Das amostras isoladas do inglúvio e cecos de aves, e identificadas por meio do método bioquímico como L. fermentum, nenhuma foi positiva pela PCR.

Há dificuldades na distinção entre $L$. reuteri e $L$. fermentum pelos testes fisiológicos convencionais e métodos bioquímicos (Reuter, 1997), mesmo eles não sendo relacionados geneticamente, como indicado pela sua diferença no mol\% de $\mathrm{G}+\mathrm{C}$ do DNA (Kandler e Weiss, 1986). Klein et al. (1998) consideraram a característica molecular como ferramenta utilizada para diferenciar essas duas espécies.

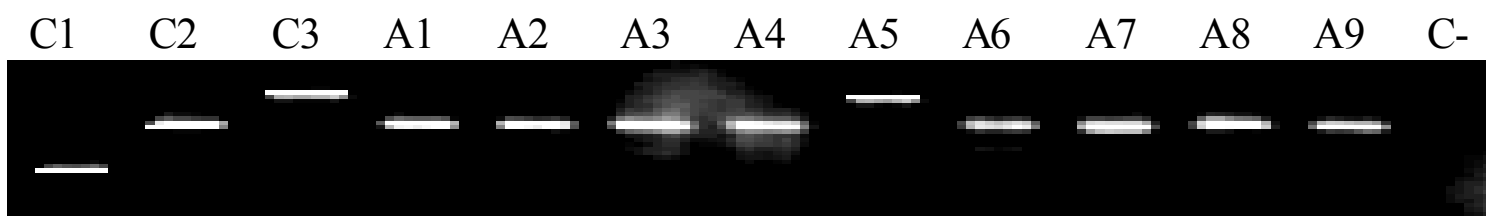

Figura 1. Eletroforese em gel de agarose dos produtos da PCR multiplex com iniciadores para $L$. fermentum (Fer3/Fer4), L. reuteri (Reu1/Reu2) e L. salivarius (Sal1/Sal2). Marcador de peso molecular 50pb. C1, C2 e C3: estirpes referência de L. fermentum CCT 3433 (192pb), L. reuteri CCT 3433 (303pb) e L. salivarius CCT $3752(411 \mathrm{pb})$, respectivamente. A1-A9: estirpes de isolados de aves (EIAs). C: controle negativo sem DNA. 
O grupo L. acidophilus consiste de outras espécies como L. crispatus, L. amylovorus, L. gallinarum, $L$. gasseri e L. jonsonii identificadas por meio da análise de homologia de DNA-DNA (Johnson et al., 1980; Lauer et al., 1980; Fujisawa et al., 1992; Pot et al., 1993; Guan et al., 2003). Pelo método bioquímico, as amostras isoladas de aves foram positivas para $L$. acidophilus e, quando testadas na PCR para identificação do grupo e espécie, as mesmas apresentaram resultado negativo (Fig. 2).

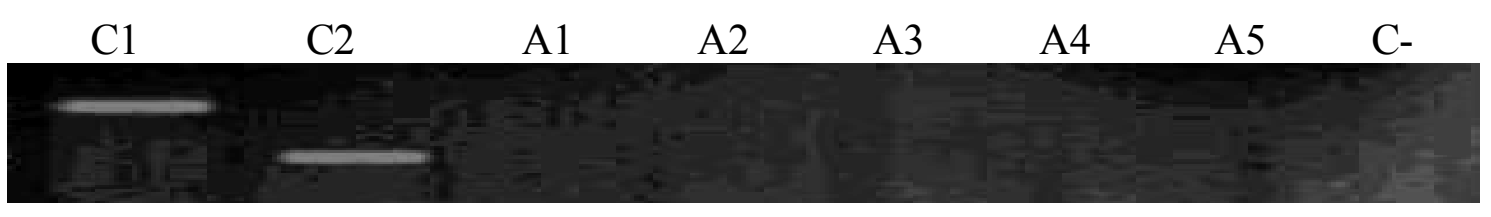

Figura 2. Eletroforese em gel de agarose do produto de PCR com iniciadores grupo-específicos ( $L U$ $\left.1^{\prime} / L a c 2\right)$ e iniciadores que amplificam segmento do genoma de L. acidophilus (Lac1/23-10C). Marcador de peso molecular 100pb. Colunas $\mathrm{C} 1$ e C2: estirpes-referência do grupo Lactobacillus acidophilus (300pb) e L. acidophilus KCTC 3111 (200pb), respectivamente. A1-A5: estirpes de isolados de aves (EIAs) negativo; C-: controle negativo sem DNA.

Considera-se importante identificar as espécies de Lactobacillus spp. presentes no ecossistema microbiano (Song et al., 2000), e são necessários métodos eficientes e simples para detectar e identificar as mesmas (Chagnaud et al., 2001). De acordo com Klaenhammer (1995), as espécies de maior incidência nos intestinos de humanos, suínos e galinhas são $L$. salivarius e $L$. reuteri. Segundo Garriga et al. (1998) $L$. salivarius é a espécie predominante no inglúvio e conteúdo intestinal de galinhas jovens, enquanto L. reuteri é espécie heterofermentativa dominante no intestino de vacas (Sarra et al., 1979).

A utilização da PCR na identificação das espécies de Lactobacillus isoladas de aves apresentou resultados discrepantes quando comparados com os resultados da fermentação de carboidratos, semelhante aos obtidos por Chagnaud et al. (2001), que, ao utilizarem o padrão de fermentação de carboidratos e PCR, verificaram que a PCR se mostrou mais discriminativa.

De Martinis (2002) considerou insatisfatória a utilização do padrão de fermentação de carboidratos como único critério para identificação das bactérias acidoláticas (LAB) porque ocorrem frequentemente variações nas fermentações, e a interpretação pode ser subjetiva.

Os iniciadores utilizados neste trabalho para identificação dos Lactobacillus foram estirpe- específicos, com base na sequência do RNA ribossomal (rRNA) da região do espaço intergênico (ISR) do $16 \mathrm{~S}$ e 23S, concordando com Stiles e Holzapfel (1997), que relataram o progresso das técnicas para estudos da relação fenotípica baseado nas análises de sequências do rRNA $16 \mathrm{~S}$ e $23 \mathrm{~S}$, pois a informação genética dessas moléculas é altamente conservada e apropriada para determinar a relação das bactérias.

Os resultados obtidos por meio do multiplex PCR, considerado de fácil reprodutibilidade e rápido para identificação das amostras isoladas de aves, foram $L$. reuteri e $L$. salivarius, e assemelham-se ao observado por Klaenhammer (1995) ao verificarem, dentre as espécies de Lactobacillus em aves, que $L$. reuteri e $L$. Salivarius estavam presentes, identificadas por meio da homologia DNA-DNA.

\section{CONCLUSÕES}

A caracterização do gênero Lactobacillus pôde ser realizada com base nos testes de coloração pelo método de Gram, catalase, produção de gás em glicose e $\mathrm{H}_{2} \mathrm{~S}$ em TSI. A identificação das espécies de Lactobacillus é mais precisa e rápida com a utilização da PCR quando comparada com a identificação pela fermentação de carboidratos, que demonstrou ser subjetiva devido às variações na fermentação de carboidratos, principalmente na diferenciação das estirpes de $L$. fermentum e L. reuteri. 


\section{AGRADECIMENTOS}

À Fundação de Amparo à Pesquisa do Estado de São Paulo (FAPESP), pelo apoio financeiro, à Coordenadoria de Aperfeiçoamento de Pessoal de Nível Superior (CAPES), às biomédicas Suzane Ramos da Silva e Glenda Niciolli da Silva, pelo auxílio na execução dos métodos moleculares no Laboratório de Patologia Molecular da Faculdade de Medicina de Botucatu, UNESP-Botucatu, SP, e ao Prof. Dr. Josias Rodrigues do Departamento de Microbiologia e Imunologia do Instituto de Biociências, UNESP-Botucatu, SP.

\section{REFERÊNCIAS BIBLIOGRÁFICAS}

CHAGNAUD, P.; MACHINIS, K.; COUTTE, L.A. et al. Rapid PCR-based procedure to identify lactic acid bacteria: application to six common Lactobacillus species. J. Microbiol. Methods, v.44, p.139-148, 2001.

COLLINS, E.B.; HARTLEIN, K. Influences of temperature on lactobacilli of nonfermented acidophilus milks. J. Dairy Sci., v.65, p.883-886, 1982.

De MARTINIS, E.C.P. Identification of meat isolated bacteriocin- producing lactic acid bacteria using biotyping and ribotyping. Arq. Bras. Med. Vet. Zootec., v.54, p.659-661, 2002.

FUJISAWA, T.; BENNO, Y.; YAESHIMA, T. et al. Taxonomic study of the Lactobacillus acidophilus group, with recognition of Lactobacillus gallinarum sp. nov. and Lactobacillus johnsonii sp. nov. and synonymy of Lactobacillus acidophilus A3 (Johnson et al., 1980) with the type strain of Lactobacillus amylovorus (Nakamura, 1981). Int. J. Syst. Bacteriol., v.42, p.487-491, 1992.

GARRIGA, M.; PASCUAL, M.; MONFORT, J.M. et al. Selection of Lactobacilli for chicken probiotic adjunts. J. Appl. Microbiol., v.84, p.125-132, 1998

GUAN, L.L.; HAGEN, K.E.; TANNOCK, G.W. et al. Detection and identification of Lactobacillus species in crops of broilers of different ages by using PCR-Denaturing Gradient Gel Eletrophoresis and Amplified Ribossomal DNA Restriction Analyses. Appl. Environ. Microbiol., v.69, p.6750-6757, 2003.
JOHNSON, J.L.; PHELPS, C.F.; CUMMINS, C.S. et al. Taxonomy of the Lactobacillus acidophilus group. Int. J. Syst. Bacteriol., v.30, p.53-58, 1980.

KANDLER, O.; WEISS, N. Regular, nonsporing Gram-positive rods. In: SNEATH, P.H.A.; MAIRM, N.S.; SHARPE, M.E. et al. (Eds). Bergey's manual of systematic bacteriology. Baltimore: Williams and Wilkins, 1986. v.2, p.1209-1234.

KANDLER, O.; STERTTER, K.O.; KÖHL, R. Lactobacillus reuteri sp. Nov., a new species of heterofermentative lactobacilli. Zentralbl. Bakteriol. Orig., C1, p.264-269, 1980.

KAWAGUCHI, I.; HAYASHIDANI, H.; $\mathrm{KANEKO}, \mathrm{K}$. et al. Bacterial flora of the respiratory tracts in chickens with a particular reference to Lactobacillus species. J. Vet. Med. Sci., v.54, p.261-267, 1991.

KLAENHAMMER, T.R. Genetics of intestinal lactobacilli. Int. Dairy. J., v.5, p.1019-1058, 1995.

KLEIN, G.; PACK, A.; BONAPARTE, C. et al. Taxonomy and physiology of probiotic lactic acid bacteria. Int. J. Food Microbiol., v.41, p.103-125, 1998.

LAUER, E.; HELMING, C.; KANDLER, O. Heterogeneity of the species Lactobacillus acidophilus (Moro) Hansen and Moquot as revealed by biochemical characteristics and DNA-DNA hybridization. Zentralbl. Bakteriol. Orig., C1, p.150-168, 1980.

LERCHE, M.; REUTER, G. Das Vorkommen aerob wachsender grampositiver Stabchen des Genus Lactobacillus Beijerinck im Darminhalt erwachsener Menschen. Zentralbl. Bakteriol. Orig., v.185, p.446-481, 1962.

MILES, R.D. Manipulation of the microflora of the gastrointestinal tract: natural ways to prevent colonization by pathogens. In: ALTECH BIOTECHNOLOGY IN THE FEED INDUSTRY, 1993, Florida. Proceedings... Florida, 1993. p.133-150.

NOUR, M. 16S-23S and 23S-5S intergenic spacer regions of lactobacilli: nucleotide sequence, secondary structure and comparative analysis. Res. Microbiol., v.149, p.433-448, 1998. 
OLIVEIRA, D.E.; BACCHI, M.M.; MACARENCO, R.S.S. et al. Human papillomavirus and Epstein-Barr virus infection, p53 expression, and cellular proliferation in laryngeal carcinoma. Am. J. Clin Pathol., v.126, p.284-293, 2006.

OYARZABAL, O.A.; CONNER, D.E. In vitro fructoolisaccharide utilization and inhibition of Salmonella spp. by selected bacteria. Poult. Sci., v.74, p.1418-1425, 1995.

PELCZAR, M.J.; REID, R.; CHAN, E.C.S. Microbiologia. São Paulo: McGraw Hill, 1981. p.1072.

POT, B.; HERTEL, C.; LUDWIG, W. et al. Identification and classification of Lactobacillus acidophilus, L. gasseri, and L. johnsonii strains by SDS-PAGE and rRNA-targeted oligonucleotide probe hybridization. J. Gen. Microbiol., v.139, p.513-517, 1993.

REUTER, G. Was ist unter Doderlein-Bakterien $\mathrm{zu}$ verstehen? In: INTERNATIONALE TAGUNG UBER INFEKTIONEN IN DER GYNAKOLOGIE, GEBURTSHILFE UND UROLOGIE, 12., 1997, Munchen. Proceedings... Munchen, 1997.

SALANITRO, J.P.; BLAKE, I.G.; MUIRHEAD, P.A. et al. Bacteria isolated from the duodenum, ileum and cecum of young chicks. Appl. Environ. Microbiol., v.35, p.782-790, 1978.

SARRA, P.G.; MAGRI, M.; BOTTAZZI, V. et al. Frequenza di bacilli lattici eterofermentati nelle feci di vitelli lattanti. Arch. Vet. Ital., v.30, p.16-21, 1979.

SARRA, P.G.; MORELLI, L.; BOTTAZZI, V. The lactic acid microflora of fowl. In: WOOD, B.J.B. (Ed). The lactic acid bacteria in health and diseases. London: Elsevier, 1992. p.3-19.

SHARPE, M.E. The genus Lactobacillus. In: .The Prokaryotes. Berlin: Springer Verlag, 1981. v.2, p.1653.

SNEATH, P.H.A.; MAIR, N.S.; SHARPE, M.E. et al. (Eds). Bergey's manual of systematic bacteriology. Baltimore: Williams \& Wilkins, 1986. v.2, p.1239.

SONG,Y.L.; KATO, N.; LIU, C.X. et al. Rapid identification of 11 human intestinal Lactobacillus species by multiplex PCR assays using group- and species-specific primers derived from the $16 \mathrm{~S}-23 \mathrm{~S}$ rRNA intergenic spacer region and its flanking $23 \mathrm{~S}$ rRNA. FEMS. Microbiol. Lett., v.187, p.167-173, 2000.

STILES, M.E.; HOLZAPFEL, H. Lactic acid bacteria of foods and their current taxonomy. Int. J. Food Microbiol., v.36, p.1-29, 1997.

TORRIANI, S.; ZAPPAROLI, G.; DELLAGLIO, F. Use of PCR- Based Methods for Rapid differentiation of Lactobacillus delbrueckii subsp. Bulgaricus and L. Delbrueckii subsp. Lactis. J. Food Prot., v.65, p.4351-4356, 1999.

ZAR, J.H. Biostatistical analysis. New Jersey: Prentice Hall, 1996. p.718. 